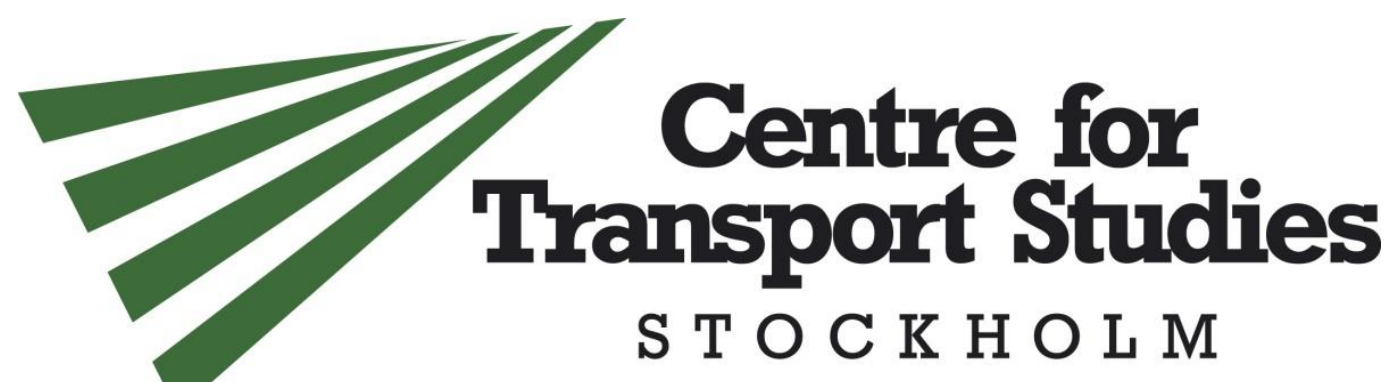

\title{
The Distance Factor in Swedish Bus Contracts How far are operators willing to go?
}

\author{
Andreas Vigren \\ Transport Economics, VTI, Swedish National Road and Transport Research Institute
}

CTS Working Paper 2017:14

\begin{abstract}
One of the factors differentiating operators the most in bus services is, arguably, the respective distances from their workplaces to the area of a procured contract. More dead running kilometers implies higher costs, and the same should affect operators' probability to participate in tenders. As previous studies have discussed, this is a relevant competitive factor, but the transport literature lacks studies aiming to assess the size of this distance factor. This paper examines what impact operators' distance to tendered bus contracts has on their probability to participate in the tender, and how this probability differs across operator types.
\end{abstract}

To address this, an econometric analysis was undertaken using probit regressions with data on tendered Swedish bus contracts over the period 2007-2015 along with operator workplace data. The results show that operators' distance from a contract has a significantly negative effect on their probability of placing a bid for the contract. While being located near the contract gives, on average, an over 90 percent probability of participating, being 10 kilometers away results in a 30 percent probability. The rival's distance to the contract also has an effect, but only to a limited extent. Large operators are found to be less affected by their distance to a contract, and they are also more inclined to bid if the procuring authority offers a depot to use

Keywords: Competitive tendering, Distance, Dead running kilometers, Bus, Entry, Competition, Participation

JEL Codes: H57, L91, L16, L11, C35

Centre for Transport Studies

SE-100 44 Stockholm

Sweden

www.cts.kth.se
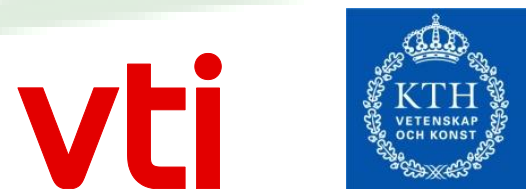



\title{
The Distance Factor in Swedish Bus Contracts How far are operators willing to go? th
}

\author{
Andreas Vigren ${ }^{\mathrm{a}, \mathrm{b}}$ \\ ${ }^{a}$ Swedish National Road and Transport Research Institute (VTI), Teknikringen 10, 11428 Stockholm, Sweden \\ ${ }^{b}$ Centre for Transport Studies (CTS), same as above
}

\begin{abstract}
One of the factors differentiating operators the most in bus services is, arguably, the respective distances from their workplaces to the area of a procured contract. More dead running kilometers implies higher costs, and the same should affect operators' probability to participate in tenders. As previous studies have discussed, this is a relevant competitive factor, but the transport literature lacks studies aiming to assess the size of this distance factor. This paper examines what impact operators' distance to tendered bus contracts has on their probability to participate in the tender, and how this probability differs across operator types.

To address this, an econometric analysis was undertaken using probit regressions with data on tendered Swedish bus contracts over the period 2007-2015 along with operator workplace data. The results show that operators' distance from a contract has a significantly negative effect on their probability of placing a bid for the contract. While being located near the contract gives, on average, an over 90 percent probability of participating, being 10 kilometers away results in a 30 percent probability. The rival's distance to the contract also has an effect, but only to a limited extent. Large operators are found to be less affected by their distance to a contract, and they are also more inclined to bid if the procuring authority offers a depot to use.
\end{abstract}

Keywords: Competitive tendering, Distance, Dead running kilometers, Bus, Entry, Competition

\section{Introduction}

When procuring bus services, the public transport authority (PTA) puts effort into designing various aspects of upcoming contracts, including traffic networks, penalties, incentives, special requirements, and so on. The contract is then put out to tender, and operators in the market are expected to enter bids for the contract. The relevant (geographical) market of the contract and its size, however, is not necessarily straightforward. Mathisen and Solvoll (2008) note that the Norwegian bus operator market has become

\footnotetext{
The author is grateful to Svante Mandell, Jan-Eric Nilsson, and Sofia Lundberg for much appreciated help, comments, and suggestions while writing this paper. Financial support from Centre for Transport Studies is gratefully acknowledged.

Email address: andreas.vigren@vti.se (Andreas Vigren)
} 
more concentrated during the last two decades, a development similar the one observed by Nilsson (2011) for Sweden, which could well have implications for the price and quality of the services tendered. For the PTAs, it is therefore important for them to have knowledge about their local competitive environment and what they can expect regarding competition for the tenders that they put out. Although bus service in itself is mobile, there is evidence that the competition for bus contracts is not. Because of the need to have access to depots (garages), the distance from the contract, or location, is crucial in providing public transport services. Being too far away implies higher costs by more dead kilometers run ${ }^{1}$ (dead running), and possibly less knowledge about the area to be serviced. Iossa and Waterson (2017) note, for London, that depots could be difficult to establish in the short run, but also that operators have depots relatively evenly spread out over the London area so that monopoly situations for contracts can be avoided. This is probably not the case when considering larger areas or multiple regions, which this paper does. The difficulties in establishing new depots will, in the long run, mean more protected markets for the incumbent operators. Also, due to the long contracts (8-10 years) and often repeatedly tendered contract areas, the loss faced by an operator might encourage it to withdraw from the area, thus reducing future competition. Local competition should, therefore, be of importance for the tendering of bus services.

The purpose of this paper is to investigate what impact operators' distance to tendered bus contracts in Sweden has on the probability to enter a bid for such tenders. The paper also considers whether there are differences in this across operator types or differences when PTAs include depots for operators to use in the contracts. These issues are relevant for the PTAs because they have implications on how to define areas for tendering and how to determine the scope for competition in their respective counties.

Operator location and distance from depots to contracts, otherwise known as the dead running distance, has been discussed in previous transport economics literature, mostly in terms of its economic consequences (Preston, 1992; Hensher et al., 2013) or in terms of procurement design (Wallis and Bray, 2001). While the hard acquisition of a depot for new operators serves as an entry barrier (Iossa and Waterson, 2017), the same also serves as a cost advantage for the depot incumbent in an area (Kennedy, 1996; Hensher and Wallis, 2005). For bus provision, Tukiainen (2008) argues that depots close to contracted areas have more common than private cost elements. Because of this, Tukiainen advised policy makers not to offer depots to the winning operators because the potentially increased competition would not translate into lower procurement costs due to the common cost elements. Cantillon and Pesendorfer (2006), on the other hand, argue for a private cost environment. Dead running has also been given more attention in the engineering

\footnotetext{
${ }^{1}$ Dead kilometers is the distance a bus drives when not in service, for example, between the depot and the start of a bus line or between bus lines when starting a new shift. This is also known as dead mileage, or deadheading.
} 
literature when trying to optimize routes or implement new bus lines efficiently. A common finding is that dead running can often be reduced by optimized driving schemes (Prakash et al., 1999; Mahadikar et al., 2015), that can reduce the cost of dead running by some 10 percent (Kepaptsoglou et al., 2009).

Few studies have, however, tried to make some assessment on what importance and magnitude distance has on participating in tenders or bids, although it is established that distance affects both participation and bids. Much of the focus is, however, on the latter. Cantillon and Pesendorfer (2007) analyzed tendered bus contracts in the London area and found that operators having depots farther away from the contract indeed submitted higher bids. This is an established result in many areas, for example, in the procurement of highway construction (Jofre-Bonet and Pesendorfer, 2003; Bajari and Ye, 2003; Lewis et al., 2011) or snow removal (Flambard and Perrigne, 2006) where costs, and consequently bids, increase with the bidder's distance to a construction site or area to be cleared. Some of these studies take into account distance in the bidder's participation decision, but they do not analyze this in more detail in order to infer the magnitude or implications of this variable or how far operators are willing to go in providing their services. An exception when analyzing bids for highway constructions is Somaini (2011) who divided distances into intervals and found that a larger distance generally increases bids, but that this differs depending on the company.

The location is also of importance when evaluating the performance of public transport services, and Hensher (2015) notes that "the failure to recognize sources of influence on cost efficiency that are not under the control of the operator and which vary by contract location is very poor analysis". In comparing how efficiently operators perform in different regimes or contracts, location arguably plays a substantial role. Even in more sophisticated efficiency analyses (for example, frontier analysis), the performance is most times, if not always, evaluated against the kilometers (or hours) run in the contract and does not consider depot location.

The rest of the paper is organized as follows. Section 2 gives a theoretical discussion on how distance affects profits and the participation decision, and Section 3 gives an overview of the Swedish operator market. In Section 4 the empirical framework is presented, and the data used in the analysis are described in Section 5. The results from the estimated models are given in Section 6 , followed by a discussion of the results in Section 7. Section 8 concludes the paper.

\section{Theoretical discussion}

As outlined in the previous section, there are good reasons to believe that for public transport services the distance from a depot to a contract affects the whether it participates in the tender. When deciding whether to participate or not, the operator evaluates its expected profit from running the contract. To enter, it must have

$$
\mathbb{E}\left[\pi_{i j m}\right]=\max _{b_{i j m}}\left[b_{i j m}-C_{i j m}\left(l_{j m}, d_{i j}, \mathbf{w}_{i}, \mathbf{x}_{j m} ; e_{i}\right)\right] \operatorname{Pr}\left(W i n \mid b_{i j m}\right)-k_{i j m}\left(l_{j m}, \mathbf{x}_{j m} ; e_{i}\right) \geq 0,
$$




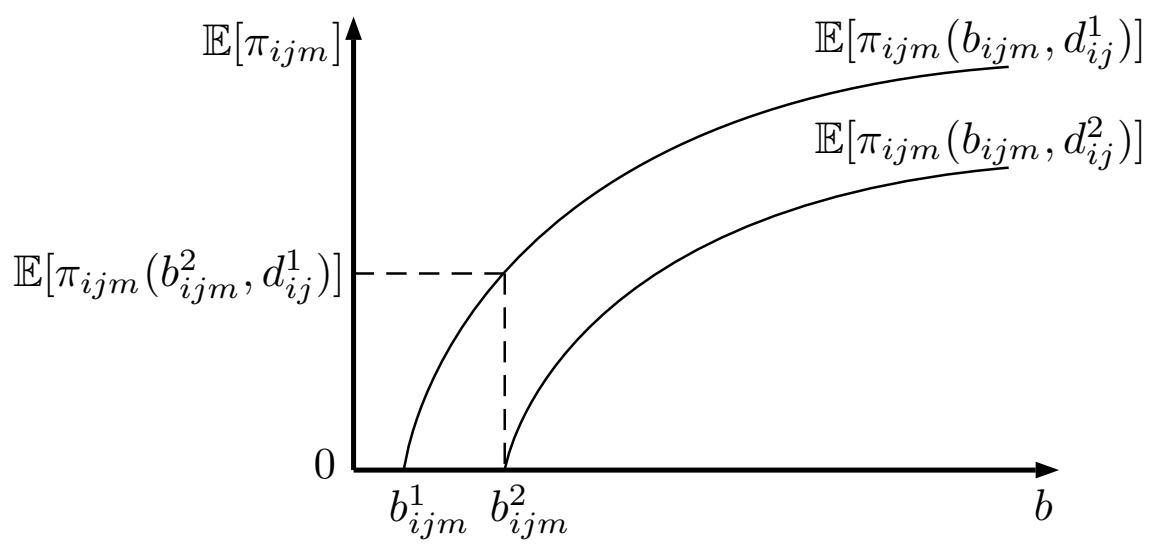

Figure 1: Dead running as a shifter of expected profits for distances $d_{i j}^{1}<d_{i j}^{2}$

where $b_{i j}$ is the bid by operator $i$ for contract $j$ in tender $m, C_{i j m}(\cdot)$ is its cost function, $\operatorname{Pr}\left(W i n \mid b_{i j m}\right)$ is the probability of winning the contract conditional on the bid, and $k_{i j m}(\cdot)$ the cost of entering the tender. This setup bears resemblance to what is used by Lundberg et al. (2015), who analyzed the use of green criteria in internal regular cleaning contracts. The components affecting the expected profit are the bus line network $l_{j}$ to be run in the contract, the distance between the operator's depot and the contract (dead running) $d_{i j}$, a vector of input factor prices $\mathbf{w}_{i}$, and a vector of contract specific properties $\mathbf{x}_{j m}$, which also can be common for the whole tender. Also, an indirect factor that affects the operator's cost and entrance cost functions is the operator's underlying efficiency $e_{i}$ in, for example, running the service, preparing bids, or knowledge of the area to be served. The operator's bid is calculated based on one or more quantities $\left(l_{j}\right)$, for example, the price $(p)$ per kilometer driven. In a simple setup, the bid would be $b_{i j m}=p * l_{j}$, but with more factors affecting the expected profit the operator instead faces a bid function

$$
b_{i j}=f\left[C(\cdot), k_{i j m}(\cdot)\right]
$$

with $f(\cdot)$ increasing in $C$ and $k$.

One important thing to note is that the operator is only paid according to the production $l_{j}$ made in the contract. That is, not for $d_{i j}$, meaning that dead running is a disadvantage, the costs of which must be recovered in the price. All else being equal, $d_{i j}$ could be viewed as a profit or cost shifter (Tukiainen, 2008; Somaini, 2011). Consider a case with a potential bidding operator and two depot locations 1 and 2 with the distances to the contract $d_{i j}^{1}<d_{i j}^{2}$. This situation is illustrated in Figure 1 where two (expected) profit functions for operator $i$ are given and that differ only in dead running distance. When the operator considers its bid, there exists a cut-off point for the bid where the expected profit turns negative, and the operator thus does not participate in the tender. Let $b_{i j m}^{1}$ and $b_{i j m}^{2}$ be these cut-off bids for location $d_{i j}^{1}$ and $d_{i j}^{2}$, respectively. Starting with the longer distance case, $d_{i j}^{2}$, the operator makes positive profits if $b>b_{i j m}^{2}$. The distance does, however, restrict its participation because it cannot cover its extra costs for dead running 
if a lower bid is placed. Were the operator instead to have access to a depot at $d_{i j}^{1}$, it would be willing to participate with even lower bids. Distance being a profit shifter is perhaps clearer when considering the expected profits of placing bid $b_{i j m}^{2}$, but only having a dead running distance of $d_{i j}^{1}$. By utilizing a closer location, the expected profit is shifted up, and the fact that distance affects participation is established. In this example, no explicit treatment of the $\operatorname{Pr}\left(W_{i n} \mid b_{i j m}\right)$ component has been made. As $b_{i j m}$ increases, the expected profit falls. Were the bid-axis to be extended, one could argue that the profit function would fall and at a certain point reach zero, at which an "upper" cut-off point could be found. This would, however, not change the implications made in the figure.

Apart from affecting costs directly, distance could also have an impact on the efficiency of the operator. Because efficiency enters the expected profit function via $C_{i j m}(\cdot)$ and $k_{i j m}(\cdot)$, distance also affects these indirectly. The intuition would be that operators close to a procured contract have local information and knowledge about the environment, information they could use to improve their operating costs according to the tendered contract. Also, being close to the contract could imply that the operator has experience from previous procurements in the area so that its cost of preparing the bid would be lower. Thus, if anything, a shorter distance to the contract improves the operator's efficiency and in turn its expected profits. Analogously with how distance affects the profit function directly, this indirect effect would imply that operators farther away would participate to a lesser extent.

\section{The Swedish operator market}

In 2015, there were about $220^{2}$ private and publicly owned bus operators of varying size in Sweden. In this study, a workplace is defined as every address where the operator has activity, for example, a depot or headquarters, as defined by Statistics Sweden. Three broad categories of operators can be defined, including large operators, cooperation companies (called "co-ops" in the reminder of the text), and other operators, and these will be discussed in turn below.

In Sweden, four operators stand out in terms of revenue - Nobina, Keolis, Arriva, and Transdev (in order of revenue). Nobina and Keolis originated from previously publicly owned Swedish companies ${ }^{3}$ and Transdev originated from the privately owned Linjebuss. Thus, these operators have a long history of operations in Sweden. Today, Nobina is listed on the stock market and is currently (in the year 2017) owned mainly by asset-management organizations, while Keolis and Transdev are owned ultimately by the French government. The fourth operator, Arriva, has been active in the Swedish market since 1999 and is owned in

\footnotetext{
${ }^{2}$ Using SCB SNI 2007-codes 49.31 (urban and suburban passenger land transport) and 49.39 (other passenger land transport not elsewhere classified). For SNI 2002, the corresponding codes are used. This number excludes companies with no employees or no revenue, as well as excluding pure coach operators and non-relevant companies (for example, PTAs or holding companies).

${ }^{3}$ Nobina Sverige originates from SJ Buss, later Swebus, and Keolis originates from SL Buss and Näckrosbuss, later Busslink.
} 


\begin{tabular}{lccl} 
& \# Members & Founded & Counties active in \\
\hline Buss i Väst (Bivab) & 31 & 1992 & $\begin{array}{l}\text { Halland, Jönköping, Kalmar, } \\
\text { Kronoberg, Skåne, Västra Götaland, } \\
\end{array}$ \\
& 20 & 1990 & $\begin{array}{l}\text { Östergötland } \\
\text { Västerbotten }\end{array}$ \\
Busspoolen & 19 & 1986 & Norrbotten \\
Centrala Buss & 9 & 1987 & Jämtland-Härjedalen \\
Centrala Buss i J/H* & 12 & 2007 & Gotland \\
Gotlandsbuss & 13 & 1981 & Värmland \\
Förenade Buss** & 5 & 1991 & Jämtland-Härjedalen, Västernorrland \\
Mittbuss & 21 & 1996 & Dalarna, Gävleborg, Södermanland \\
Sambus & & Uppsala, Östergötland \\
\hline
\end{tabular}

* Centrala Buss i Jämtland/Härjedalen. Source: Website of each cooperation company or annual reports

** As of March 2016, the Förenade Buss have filed for bankruptcy.

Table 1: Cooperation companies in Sweden 2015

full by Deutsche Bahn, a German state-owned transport company. These four are labeled as large operators in the paper and have placed bids in tenders in various parts of Sweden. Furthermore, and something that will be returned to later, these operators should have the resources to keep track of the public transport market in the whole country and may, if they want, place a bid wherever the tender is. Their organizational capacity is arguably high, as well as their knowledge of organizing new local units. This will be returned to later when defining the variables that were included in the analysis.

The second type of operators is called cooperation companies. A co-op is formed by two or more small or mid-size (that is, not large) operators in a certain geographical area with the purpose of enjoying economies of scale both in production, coordinating the companies' resources, and purchasing benefits (large-scale rebates on fuel and vehicles). By doing this, they are able to bid for larger contracts than the members alone could do. This type of cooperation is common in Sweden where currently seven co-ops are active ${ }^{4}$ as of 2016, most being more than 20 years old (1). As shown in the Table 1, the number of members varies among the co-ops, as do their geographical areas. A member of a co-op is expected not to place bids on its own. Rather, the members in a co-op agree upon which areas to bid for and then place bids jointly as a group. Therefore, if two members of the same co-op have workplaces within a contract area, the co-op as well has two workplaces. However, the co-op is only counted as one bidder no matter the number of workplaces in an area, which reduces the number of potential bidders. This in turn also reduces the number

\footnotetext{
${ }^{4}$ Until 2015, Förenade Buss was present in the market but, it filed for bankruptcy in 2016. Another company is Together AB, which is a "parent-co-op" with co-ops as members. In this paper, Together AB is not considered as a bidding unit.
} 
of actors on the market competing for contracts, and could imply collusion. In principle, an operator could be a member of several co-ops, but because this is the case only for a few operators such a situation is not considered in this paper.

The third and last operator type contains the rest of the operators, and these are regarded as small or mid-sized operators belonging to the type "other operators". That is, they are not large operators nor are they members in a co-op. These operators are likely not to have the same capacity in their bidding behavior as the large operators, and thus they are more restricted geographically. This is also the reason for why some are instead in co-ops, but not all. Some 130 operators belong to this group.

Figure 2 illustrates the geographical location of operators' workplaces in 2007-2015. The map shows considerably more operators in the south of Sweden, but not so many co-ops in the lower south, except for Gotland. In the upper southern part, co-ops are found mainly in the counties of Västra Götaland, Värmland, and Uppland, although they are present elsewhere as well. Large operators are relatively evenly spread across the country, but with reduced presence in the north. Finally, turning to the middle and the north of Sweden, operators belonging to a co-op are dominating the map, especially in Västernorrland and Västerbotten. Because of the presence of co-ops, their bidding behavior as a single unit must be taken into consideration, which is discussed in more detail in the framework for the empirical framework below.

\subsection{Supplier selection}

Most subsidized public transport services in Sweden are competitively tendered, and this has been the case since the late 1980s. The 21 tendering PTAs are independent units organized by each county, although transport services can overlap between PTAs. The PTAs regularly tender contracts for various transport modes, but the largest share of the traffic is by bus (Transport Analysis, 2017), which is the focus of this paper.

For a tender, the PTA compiles enquiry documents, which essentially are the detailed specifications of how the service should be run by the winning operator. These documents are generally quite substantial and include information about requirements on the operators in terms of vehicles, personnel, and so on, as well as information on the contract area, frequency, and bus routes. These can be grouped together as contract characteristics. Given the enquiry document, operators interested in providing the requested service prepare and submit bids based on the conditions posed by the PTA. The contract characteristics, as well as the operational environment, affect the number and value of bids that a PTA receives (Vigren, 2017).

For more on the tendering process for Swedish public transport, see Vigren (2017). 
- Coop

$\triangle$ Large operator

- Other operators

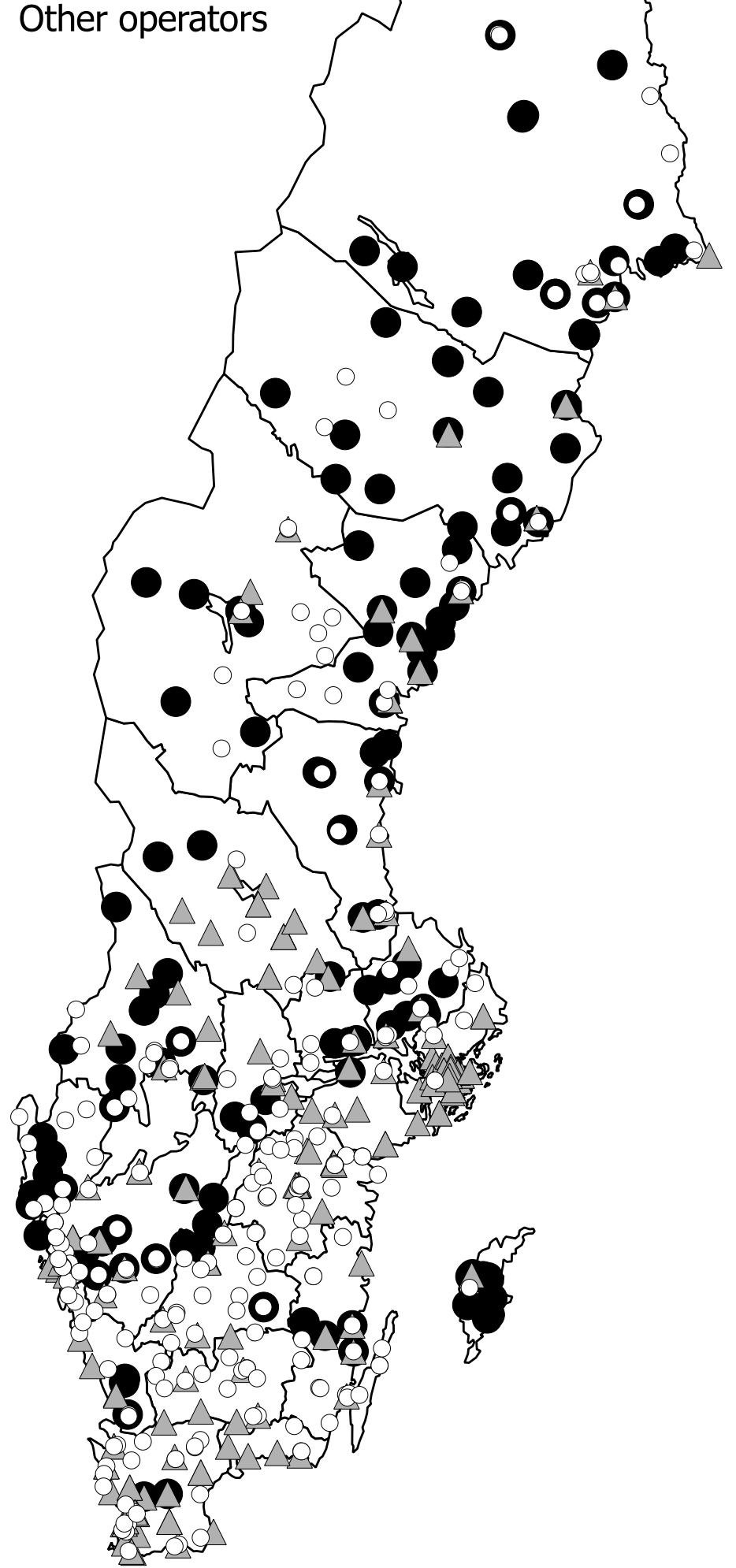

Figure 2: Map of bus operator workplaces, 2007-2015. 


\section{Empirical framework}

The econometric methodology is presented here, starting with a model to estimate the impact of distance on the probability to participate in a tender. Consider the baseline model equation

$$
y_{i j m}=\alpha+\beta \ln \left(d_{i j}\right)+\gamma \ln \left(r_{j}\right)+\boldsymbol{\delta}^{\prime}\left(\mathbf{x}_{j m}\right)+c_{i}+\epsilon_{i j m},
$$

where $y_{i j m}$ is the outcome variable of interest for operator-workplace $i$, contract $j$, and procurement $m$. The outcome variable is binary and takes the value 1 if operator $i$ has placed a bid for contract $j$ (participated), and zero otherwise. $d_{i j}$ is operator $i$ 's shortest distance to contract $j, r_{j}$ is the rival's distance to the contract, $\mathbf{x}_{j m}$ is a vector of control variables describing the tendered contract, $c_{i}$ contains operator-workplace-specific dummy variables, or fixed effects, and $\epsilon_{i j m}$ is an error term with a normal distribution. $c_{i}+\epsilon_{i j m}$ can also be regarded as the composite error term. Lowercase Greek letters are scalars or vectors (boldface) of the parameters that are to be estimated. Observations are at the operator-workplace and contract level.

The main variable of interest, $d_{i j}$, is measured in kilometers. If the operator has more than one workplace, the shortest distance from any of its workplaces to the contract is used. Further, due to the nature of transport, the contract location is not one single point but rather one or more bus lines spanning an area. However, the distance variable needs a single distance in the model, and thus defined location of the contract needs to be identified. Although previous studies do not specify in detail how the distance measure is constructed, it is likely to be the distance to the center of contract area (often project site). This might, however, be arbitrary or inaccurate if the area is widespread as in the case of bus routes. Instead, because the bus lines and routes of a contract are known in the contract data, this information is used to measure the distance from each workplace to the closest start or endpoint of every bus line in a contract. The distance variable can then be constructed by taking, for example, the median distance to a workplace for all bus lines in a contract, which is indeed what was used in the analysis presented here. This means that the variable definition takes into account whether the operator has several workplaces that could be used in combination to achieve less dead running compared to the situation where all vehicles depart from the same spot. Also, each operator only has one distance measure for each contract.

A variable of secondary interest, but related to the distance variable described above, is the second closest operator's distance to the contract, $r_{j}$. The idea is that for contracts where the second closest operator is farther away, there is less competition. In turn, this could increase the probability to participate if more market power can be extracted by the operator closest to the contract. Note that the variable does not vary within a contract, only across contracts. This variable will be called the rival's distance in the reminder of the paper.

The vector $\boldsymbol{x}_{j m}$ contains control variables of secondary interest in this paper, and these control for heterogeneity in contract characteristics and operational environment. These are the same variables as included in Vigren (2017) when estimating the number of bidders in bus contracts, which are arguably 
relevant also for the analysis in this paper. Although described below, more detailed information on the definition and construction of these variables is found in Vigren (2017). The included control variables are listed in Table 2, which also gives descriptive statistics for the variables. Vehicle kilometers, the number of bus lines, and the median length of these lines measure the size and type of the contract. While more kilometers are run in larger contracts, more urban contracts arguably have more but shorter lines. Further contract-specific variables are contract length, which measures the duration of the contract, a dummy for if EMAT is used, and a dummy variable indicating if the specific contract was allowed to be combined with other contracts in the tender. Finally, two dummy variables are included to control for whether some form of passenger or quality incentive payments are included in the contract. Three variables relating to the operational and competitive environment are also included. The first two are the number of potential bidders in the contract area of the tender and the population density of the area. The third is the number of simultaneous tenders occurring at the same time as a particular tender.

When estimating the effect of a specific variable on an outcome, it is important that the effect is properly isolated or identified. Just as it must control for observable factors, like the ones in $\mathbf{x}_{j m}$, a proper model must also address the unobserved factors. In this analysis, much of the unobserved variation should, arguably, be on the operator side. While there might be unobserved heterogeneity in the contracts as well, this paper mainly analyzes the operator-dimension and uses data in an operator-workplace dimension. The operators are heterogeneous in their cost structure, strategies, and size, which should all affect the outcome variable. Therefore, operator-workplace fixed effects are indicated with $c_{i}$ in Equation (3).

\subsection{Extensions}

It is not unlikely that different operators behave differently in their decisions to participate, as discussed in the previous sections. Heterogeneity could thus arise because of different entry strategies, scale economies, and local knowledge. A first extension of the baseline model in Equation 3 is to include interaction variables on the distance and the two groups of large operators and co-ops, with other operators acting as the reference group. The expectation is that distance will matter less (there will be a positive coefficient) for larger operators in their participation decision, the primary reason for this being that such operators arguably have more experience in establishing new units across the country and are able monitor the whole country for tenders. While not considered in this paper, the knowledge on how to find and rent depots where such an operator is not established might also be higher among large operators, thus making the distance from existing depots less important. For co-ops, the expected sign is not so straightforward. Although co-ops are larger units than their single member operators, it is not clear whether they exhibit similar economies of scale and knowledge advantages as the large operators. Because co-ops are made up of smaller operators, 
their interests might also lie in the local markets only. On the other hand, co-ops might be able to utilize their networks of depot across their members and thus be able to coordinate themselves better concerning distance.

Another extension is made for cases where the PTA offers a depot with the contract. All else being equal, including a depot creates a minimum distance of dead running that would indeed benefit operators that are not established close to the contract, and the reduction of this and associated entry barriers might stimulate competition. Therefore, the expected coefficient would be positive. However, the depot might be a disadvantage for those already close the contract site for the very same reason. If these operators believe that inclusion of a depot will attract more participants and that they themselves are a less efficient operator, they might seek elsewhere for tenders or bid for fewer contracts. If the depot is mandatory to use, this effect might be amplified because local operators would, in the worst case, have to use two depots and have double the costs. In addition to the main effect, depot included, interaction variables were created with operator-types. The interaction variable coefficients is expected to be positive for large operators, implying they would be more willing to participate if a depot were offered with the contract, while the signs are uncertain for the co-op-interaction and main effect coefficients.

\subsection{Estimating model}

Given the binary dependent variable, a probit model was used. Although a linear probability model, basically a linear regression of a binary variable, could be used, that model's shortcoming in not restricting the probability interval between 0 and 1 (Greene, 2003) calls for a discrete choice model.

An issue that needs to be addressed when estimating discrete choice models with panel data using maximum-likelihood methods is the incidental parameter problem (Neyman and Scott, 1948; Lancaster, 2000). In a standard panel data case with fixed effects and a cross-section $(\mathrm{N})$ over time (T), one wants to estimate $\mathrm{N}$ fixed effects, or incidental, parameters. However, because the number of parameters to estimate is increasing in $\mathrm{N}$, but fixed for $\mathrm{T}$, the asymptotic properties of the maximum likelihood estimator do not hold, and the estimates will be inconsistently estimated (Wooldridge, 2010). While the data used in this paper are rather a cross-section of operators (which would correspond to $\mathrm{N}$ above) over contracts, similar concerns might arise, and the parameter of interest, $\beta$, might be biased. For larger numbers of $\mathrm{T}$, however, the bias might not be very substantial, (Greene, 2003). This might be the case in this paper because the number of contracts is not small. Nonetheless, this potential issue will still be addressed. An estimator that copes with the incidental parameters problem is the correlated random effects probit model (Mundlak, 1978; Chamberlain, 1980, 1982), which expands the baseline Equation 3 as

$$
y_{i j m}=\alpha+\beta \ln \left(d_{i j}\right)+\gamma \ln \left(r_{j}\right)+\boldsymbol{\delta}^{\prime}\left(\mathbf{x}_{j m}\right)+\boldsymbol{\eta}^{\prime}\left(\overline{\mathbf{x}}_{i j m}\right)+v_{i}+\epsilon_{i j},
$$


with $\boldsymbol{\eta}^{\prime}\left(\overline{\mathbf{x}}_{i j m}\right)+v_{i}=c_{i}$ and $\overline{\mathbf{x}}_{i j m}$ being a vector containing the average of the control variables over operator workplace. $\overline{\mathbf{x}}_{i j m}$ also contains the averages of $d_{i j}$ and $r_{j}$. The corresponding averages of the interaction variables are also included for proper estimation, as suggested by Schunck (2013). The estimated effect on $\beta$ is thus the effect of changing $d_{i j}$ while holding the averages fixed (Wooldridge, 2010). The model is estimated using a random effects estimator.

\section{Data}

The data used in this paper were made up of two main datasets, contract data and operator data, that both span the years 2007 to 2015 . The data on bus services originated from the tender enquiry documents and awarding protocols of the running bus contracts in Sweden as of December 2015. Because there is no single source where running public transport contracts are noted, four sources have been used to identify these, including VISMA Opic, the EU TED (Tenders Electronic Daily), the contract data collection of Transport Analysis, and the procurement schedule of Svensk Kollektivtrafik, a trade organization for the PTAs. Because none of these sources contain complete information, they have been cross-referenced to identify all tenders during the study period. Also, all PTAs were contacted to complete this information (except Västmanland, where no public traffic is tendered). The result is a more or less complete list of areas and procurement years for all bus tenders with a start of operations sometime in the years 2007 to 2015. Using this information, the enquiry documents and awarding protocol were requested from each PTA for every procurement. The information of interest in the documents has been compiled to allow quantitative analysis, and most of the variables presented in the previous section stem from this source. For this paper, 268 contract (areas) in 72 procurements were analyzed, which should constitute all contracts of public transport bus services in all Swedish counties, excluding the counties of Kronoberg, Västmanland, Västerbotten, and Norrbotten. These four counties were excluded because they do not procure services, because they use a different awarding method than the rest of the country, or because the counties' traffic is significantly different compared to most other public transport. For more on these exclusions, see the discussion in Vigren (2017), who also used the same contract data. The enquiry documents gave information on vehicle kilometers (logged), the number of bus lines, contract length, whether EMAT or combinatory bidding was used, and any forms of incentive payments.

To geographically locate the contracts, information about the bus lines was mapped with Samtrafiken's GTFS data (essentially digital timetables). Knowing the PTA and bus line numbers of each contract from the contracting data made it possible to identify each line's route and stops, where the latter is geocoded in the GTFS data. The collection of lines, in turn, formed the route network of each contract with corresponding 
coordinates, and this gave the median line lengths (logged), population density (logged), and number of potential bidders within $25 \mathrm{~km}$ of the contract area ${ }^{5}$. The population density data originated from Statistics Sweden.

The operator data were from Statistic Sweden's business register, which contains address and sector information about all companies' workplaces. An extract from the database for sector-codes ${ }^{6}$ (SNI) relating to public transport operators was taken for the years 2007-2015, and the resulting list was further cleaned to only include active operators that have public transport operations. This selection is identical to the one made in Vigren (2017). Note also that operators that have never participated in the tender were excluded due to the model design ${ }^{7}$. For a workplace to be included in the estimation sample, the operator needed to have that as a workplace address the year before the tender. In addition, in cases where operators were incumbents of a depot offered by a PTA, those workplaces were not considered to be workplaces of those operators. This is because the PTA owns the depot, which can be used by any winner of the contract, and not correcting for this would produce an "incumbent bias" where incumbents seem to have depots that they do not. The coordinates of workplace addresses were extracted using Google Maps API and QGIS. The operator and coordinate information made it possible to map this to the contract data, and this allowed each operator's closest workplace to each bus line to be identified for all lines in the contract data. Accordingly, the median distance could be calculated. In the analysis, the log median distance was used both for the operator's distance and the rival's distance due to the skewed distributions. A sensitivity test using the average distance was also conducted.

The observations for co-ops were handled separately. Coops are single units made up of several minor operators that bid as one unit; therefore, the workplaces of members are assigned to the co-op directly. The 130 individual members were separated into eight co-ops, or operators.

Table 2 provides descriptive statistics for the model variables, and the variables in focus in this paper are discussed here. The median distance from operators' workplaces to the contracts appears large at 242 kilometers. However, this is an artifact of the research design. Because each workplace gets a distance to each contract, most workplaces will not be close by. To get some more details on this variable, one can instead turn to Table 3 where the average and median distances for the five closest operators are shown. For the median contract, the closest operator is only 3 kilometers away, and the fifth closest is about 35

\footnotetext{
${ }^{5}$ It was shown in Vigren (2017) that the range chosen for this variable affects the estimate. Therefore, the narrowest range in that paper was used here.

${ }^{6}$ Using SCB SNI 2007-codes 49.31 (urban and suburban passenger land transport) and 49.39 (other passenger land transport not elsewhere classified). For SNI 2002, the corresponding codes are used.

${ }^{7}$ These operators have zeros across all observations, and thus produce a "perfect prediction"
} 


\begin{tabular}{lccccc} 
& Mean & Median & SD & Min & Max \\
\hline Participation & 0.049 & 0 & 0.21 & 0 & 1 \\
Median distance (km) & 241.7 & 210.8 & 169.7 & 0.015 & 975.6 \\
$\quad$ Distance X Large operator & 98.4 & 62.2 & 105.5 & 0.015 & 620.6 \\
$\quad$ Distance X Coop operator & 342.5 & 310.0 & 233.6 & 0.22 & 975.6 \\
Rival's distance (km) & 13.2 & 10.2 & 11.8 & 0.031 & 78.9 \\
Depot included (0,1) & 0.25 & 0 & 0.43 & 0 & 1 \\
$\quad$ Depot X Large operator & 0.015 & 0 & 0.12 & 0 & 1 \\
$\quad$ Depot X Coop operator & 0.025 & 0 & 0.16 & 0 & 1
\end{tabular}

\section{Continuous control variables}

$\begin{array}{lccccc}\text { Vehicle km. (-000 km) } & 1849.1 & 897.4 & 2942.1 & 4.00 & 23700.6 \\ \quad & 13.6 & 13.7 & 1.32 & 8.30 & 17.0 \\ \text { Lines (\#) \#icle km.) } & 11.6 & 8 & 12.3 & 1 & 80 \\ \text { Median line length (km) } & 26.8 & 24.9 & 14.6 & 1.68 & 110.3 \\ \quad 3.13 & 3.22 & 0.59 & 0.52 & 4.70 \\ \quad \text { ln(Median line length) } & 23.7 & 23 & 11.5 & 6 & 58 \\ \text { Potential bidders (\#) } & 7.71 & 8 & 3.10 & 2 & 15 \\ \text { Simultaneous tenders (\#) } & 1563.8 & 1296.8 & 772.0 & 561.4 & 4226.5 \\ \left.\text { Population density (pop/ } \mathrm{km}^{2}\right) & 7.25 & 7.17 & 0.44 & 6.33 & 8.35 \\ \quad \text { ln(Population density) } & 7.29 & 8.01 & 1.67 & 2 & 10.5\end{array}$

$\underline{\text { Indicator control variables }}$

\begin{tabular}{llllll} 
EMAT & 0.45 & 0 & 0.50 & 0 & 1 \\
Combinatory bidding & 0.54 & 1 & 0.50 & 0 & 1 \\
Passenger incentives & 0.51 & 1 & 0.50 & 0 & 1 \\
Quality incentives & 0.36 & 0 & 0.48 & 0 & 1 \\
\hline
\end{tabular}

18428 observations. 268 contracts. 74 operators with 574 unique workplaces. 


\begin{tabular}{lcc} 
& Median & Mean \\
\hline Closest distance & 2.71 & 6.79 \\
2nd closest distance & 12.6 & 16.5 \\
3rd closest distance & 22.7 & 26.3 \\
4th closest distance & 28.1 & 34.8 \\
5th closest distance & 34.9 & 43.7 \\
\hline
\end{tabular}

Table 3: Five closest operators' median and mean distances to a contract

kilometers away. While 35 kilometers is probably too far of a distance for dead running, the descriptives still indicate that there should be some local competition. In the sensitivity analysis, the maximum distance was gradually lowered to determine whether the results would be altered if only considering nearby operators.

The descriptive statistics validated the pattern of Figure 2 where large operators' workplaces were more evenly spread out across the county. The median distances for these operators (98 km, on average) were substantially lower than the sample and co-op median.

Turning to the rival's distance, the median value is 10 kilometers, indicating that operators cannot count on being the only operator close to the contract. Finally, a depot is included in 25 percent of all tendered contracts. This figure includes both voluntary use and cases where the operator is forced to use it.

In total, 74 operators are in the sample used in the analysis and is lower than the 220 operators mentioned before. There are three reasons for this. Firstly, the sample is corrected for that bidders in co-ops bid with their respective co-op company. Secondly, operators in the two northmost excluded counties is removed. Finally, some operators are removed because they did not place any bid in the contract data, which would imply perfect predictions in the probit model (all observations of the operator are zero in the dependent variable). The model used 18,428 observations and implied an unbalanced panel. The reason for this is that not all operator workplaces were present in every year included in the data.

\section{Results}

Presented in this section are the results from the estimated participation models. Four estimated models are presented, with the first including the distance and rivals' distance variables, the second and third with extensions on operator type and included depot, and the fourth a model where the variables from the second and third models are combined. In the tables, control variables are not presented because these are not the focus of the paper. These can be found in the full results in Table A.5 in the appendix. McFadden's Psuedo-R2 (McFadden, 1974) and BIC statistics are included. All models use cluster-robust standard errors at the operator-workplace level. 


\begin{tabular}{|c|c|c|c|c|}
\hline & I & II & III & IV \\
\hline \multirow[t]{2}{*}{$\ln ($ Median distance $)$} & $-0.664^{* *}$ & $-0.769^{* *}$ & $-0.664^{* *}$ & $-0.760^{* *}$ \\
\hline & $(0.053)$ & $(0.086)$ & $(0.053)$ & $(0.084)$ \\
\hline \multirow[t]{2}{*}{$\ln$ (Rival's distance) } & $0.072^{*}$ & $0.072^{*}$ & $0.082^{* *}$ & $0.080^{* *}$ \\
\hline & $(0.031)$ & $(0.031)$ & $(0.030)$ & $(0.030)$ \\
\hline \multirow[t]{2}{*}{ Large $=1 * \ln ($ Median distance $)$} & & $0.332^{* *}$ & & $0.305^{* *}$ \\
\hline & & $(0.103)$ & & $(0.100)$ \\
\hline \multirow[t]{2}{*}{ Coop $=1 * \ln ($ Median distance $)$} & & 0.130 & & 0.125 \\
\hline & & $(0.139)$ & & $(0.136)$ \\
\hline \multirow[t]{2}{*}{ Depot included $=1$} & & & $-0.414^{* *}$ & $-0.420^{* *}$ \\
\hline & & & $(0.126)$ & $(0.132)$ \\
\hline \multirow[t]{2}{*}{ Large $=1 *$ Depot $=1$} & & & $1.164^{* *}$ & $1.093^{* *}$ \\
\hline & & & $(0.216)$ & $(0.222)$ \\
\hline \multirow[t]{2}{*}{ Coop $=1 *$ Depot $=1$} & & & 0.015 & 0.018 \\
\hline & & & $(0.295)$ & $(0.285)$ \\
\hline Controls & Yes & Yes & Yes & Yes \\
\hline Company fixed effects & Yes & Yes & Yes & Yes \\
\hline Obs. & 18428 & 18428 & 18428 & 18428 \\
\hline (McFadden's) Pseudo-R2 & 0.27 & 0.29 & 0.29 & 0.29 \\
\hline $\mathrm{BIC}$ & 3568 & 3553 & 3572 & 3577 \\
\hline
\end{tabular}

** $p<0.01, * p<0.05$. Cluster robust standard errors at operator-workplace level in parenthesis

Table 4: Results table

Across all models, the (median) distance coefficient has a significant negative impact on participation, implying that the farther from the tendered contract an operator has a workplace, the lower the probability that it will bid on the tender. This is the same finding as in some previous studies in other areas, mentioned in Section 1. It is important to note that this is the average effect across all operators. The average probability of participating is estimated for different values of the distance variable, ranging from 1 to 20 kilometers, and these probabilities are plotted in Figure 3, holding all other variables at their means. The figure shows that if the operator has close to zero ${ }^{8}$ dead running kilometers, there is a probability close to

\footnotetext{
${ }^{8}$ An operator never lies exactly on the start of a line, but sometimes very close. Therefore, this number is never zero.
} 
one that it will bid on the tender. However, this probability decreases for larger distances. An operator having 10 kilometers dead running has about a 30 percent probability to enter a bid. For distances over 20 kilometers, this probability falls below 15 percent.

The coefficient of the rival's distance in this model is positive and significant. It also turns out that the impact of this coefficient depends on an operator's "own" distance to the contract, meaning that the impact of the rival coefficient is larger if both the operator in question and its rival's distances from the contract are small. Figure 4 illustrates this relationship in a contour graph, giving the probability of participating in a tender for different levels of an operator's own distance (y-axis) the rival's distance (x-axis) to the contract. This figure tells the same story as Figure 3; that the further away an operator is from a contract the lower the probability of entering the tender. When also varying the rival's distance, a pattern arises. First, for an operator close to the contract, the rival's distance does not influence the participation decision, and the probability of participating remains equally as high regardless of the rival's distance. Second, the rival's distance is more important the farther away the operator's own workplace is from the contract. In the range of 5-10 kilometers for the operator's own distance, having a rival farther away can increase the probability by some six percentage points. This effect does, however, diminish for larger values of rival's distance. In essence, the rival's distance from the contract affects the operator's participation decision, but only with small magnitudes. The operator's own distance is the dominating factor for participation.

Turning to Model II, allowing the distance coefficient to vary with operator type lowers the estimate of the distance coefficient, which does also change the interpretation with the reference category, which is now the category of all other operators. The interaction variable on the distance and being a large operator has a positive and significant coefficient, implying that distance affects these operators to a lesser degree relative to the other operators. The corresponding estimate for co-ops is non-significant, and thus does not differ from the reference category. Ideally, one would want to calculate the probabilities of entering a bid for the three operator types, like in Figure 3. However, how to do this is not straightforward. The interactions in Table 4 give the slopes for such probabilities over a range of values of the distance. However, the intercepts are included in the fixed effects, which are not explicitly estimated. Although the Mundlak model by construction allows the inclusion of the main effect (a dummy variable indicating a large operator and co-op, respectively), there are arguments that the causal interpretation of this coefficient is uncertain (Wooldridge, 2010). To avoid ambiguously predicted probabilities, the operator-interaction effects are not estimated. However, the result that large operators are less affected by how far away from the contract they are (that is, a shallower slope) remains.

Model III expands the model to include depot-related variables, and here the main effect is negative and significant. This would imply that operators in the reference group are less prone to participate in a tender if the PTA offers a depot in the contract. The interaction with being a large operator is positive and significant, while the interaction with being a co-op is non-significant. Again, the proper main effects of the 


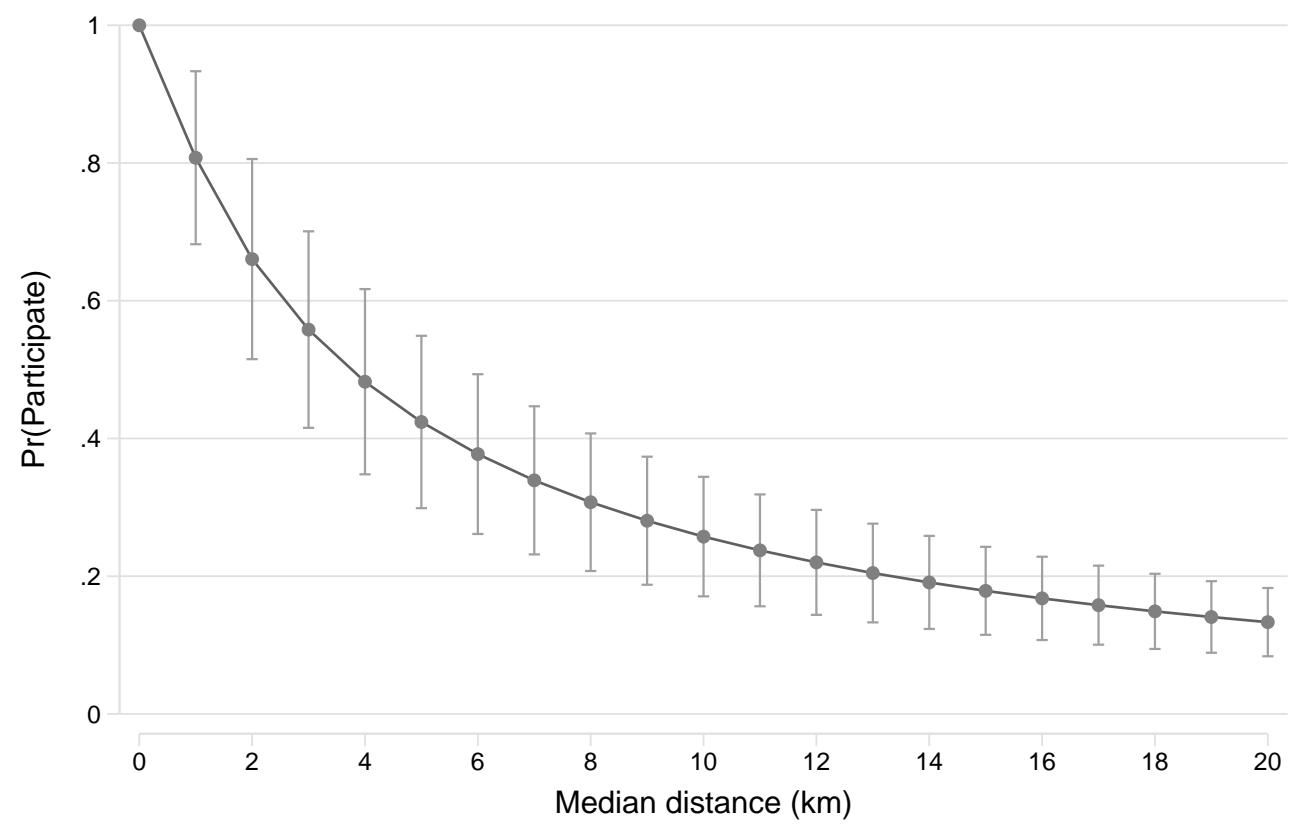

Figure 3: The average probability of participating by distance, based on model IV.

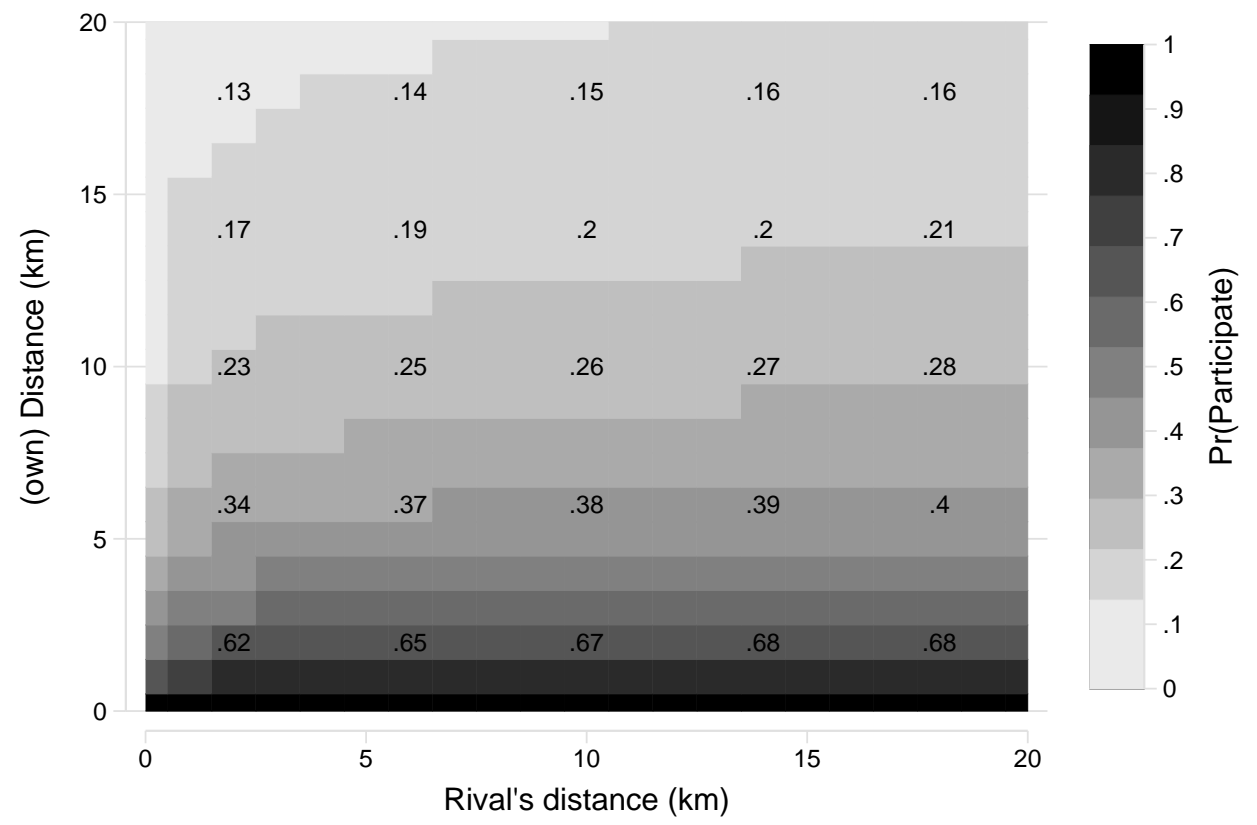

Figure 4: The average probability of participating according the operator's own distance and rival's distance, based on model IV. Numbers in the contour plot show the estimated probabilities of participation. 
operators (or operator types) cannot be inferred here, and thus the actual probability of entering a bid per operator type cannot be inferred either. The relative operator effect across operators when including a depot in the contract can, however, be interpreted as above. Because one could suspect that depots are included mostly in large contracts, Model III was rerun with the additional variable of the interaction between depot and vehicle kilometer. The positive and significant effect of large operators and depot remains, while the previously negative estimate of -0.414 for the reference category other operators is now insignificant. Thus, the inclusion of a depot seems not to lower (nor raise) the rate at which other operators and co-ops participate.

For the last model, Model IV, no major deviations from the estimated coefficients in models II and III are found, and the previous inferences are unchanged.

In Table A.5, an additional model was run where distance variables were excluded (Model V). The Pseudo-R2 statistic is close to zero, and BIC is low, implying that distance is important in explaining the participation decision. In Models I-IV, the same statistics were considerably higher.

\subsection{Sensitivity analysis}

Some additional analyses were made in order to infer how sensitive the results are to changes in the design of the regression analysis. First, the sample was reduced to not include operators that have a workplace over a certain distance from the tendered contract because one could argue that it would not be relevant to include operators who are too far away as it would be hard to earn profits, and therefore self-select out of the tender. The intervals chosen were $25,50,100,250$, and 500 kilometers, and the unrestricted interval used in Model IV was also included as a baseline case. The full results are given in Table B.7.

Focusing on the results of the median distance and rival's distance coefficients, it is clear that the coefficient estimates increase (decrease in absolute terms) for smaller distances. The standard errors also increase, indicating less precision. The rival's distance has an insignificant coefficient for the $100 \mathrm{~km}$ model. Despite the coefficient differences, however, one must consult the marginal effects in order to infer whether the magnitudes changed because the sample changed as well. The marginal effects are plotted in Figure 5, and the marginal effect from Model IV plotted in Figure 3 is included as the reference case. The overall conclusion is that the probability of participating shifts upwards the narrower the interval, by at most some 20 percentage points in the $25 \mathrm{~km}$ case. The standard errors also increase ${ }^{9}$. None of the estimated marginal effects are statistically significantly different from the reference case, except for the $25 \mathrm{~km}$ and $50 \mathrm{~km}$ case. Thus, this indicates that the chosen interval does in fact matter for the participation probability of the operator. Although the appropriate range is not straightforward to choose, this result is important to note.

\footnotetext{
${ }^{9}$ Confidence intervals are not included because these obscure the figure and cannot be visually separated because they overlap to a large extent.
} 


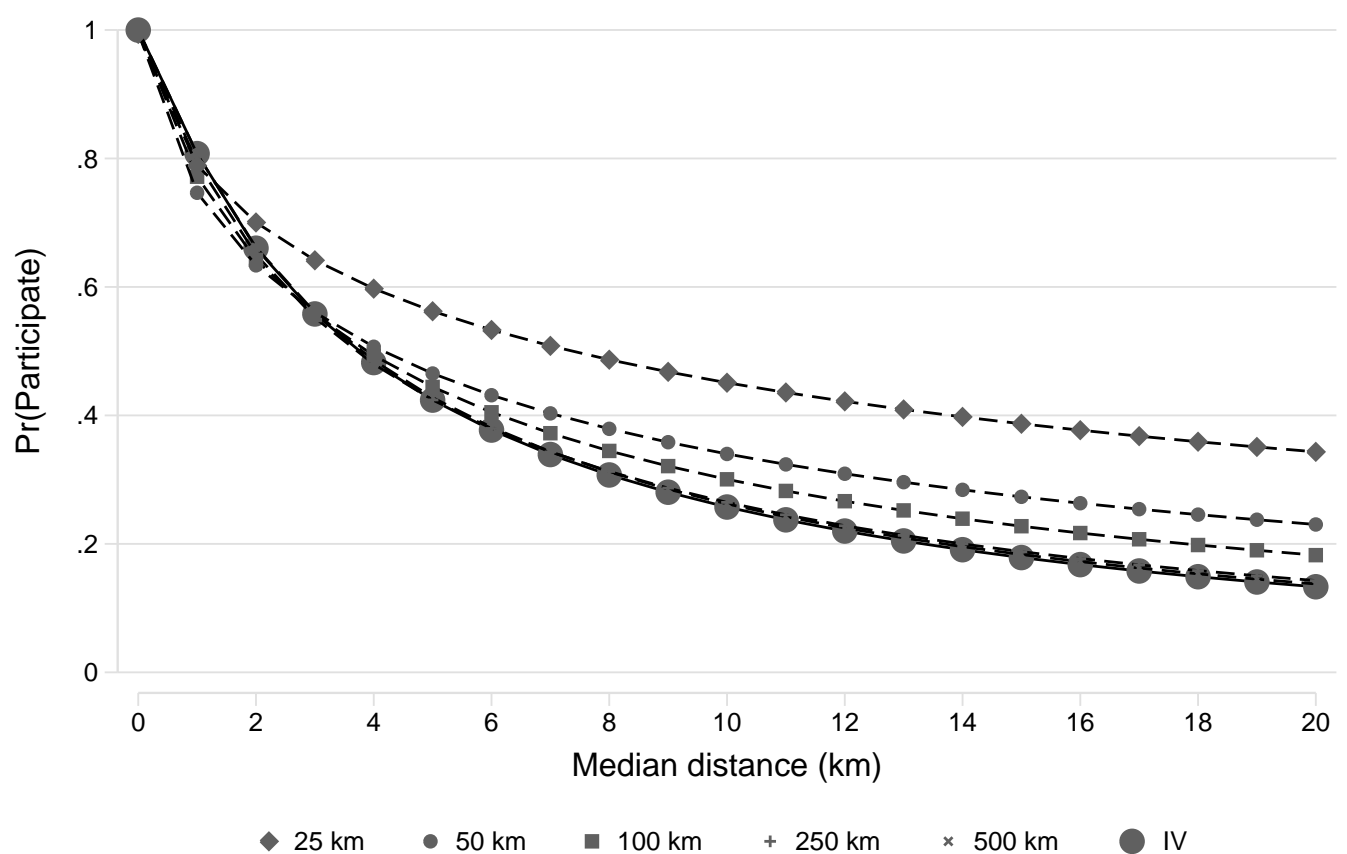

Figure 5: Average probability of participating by varying the maximum distance intervals.

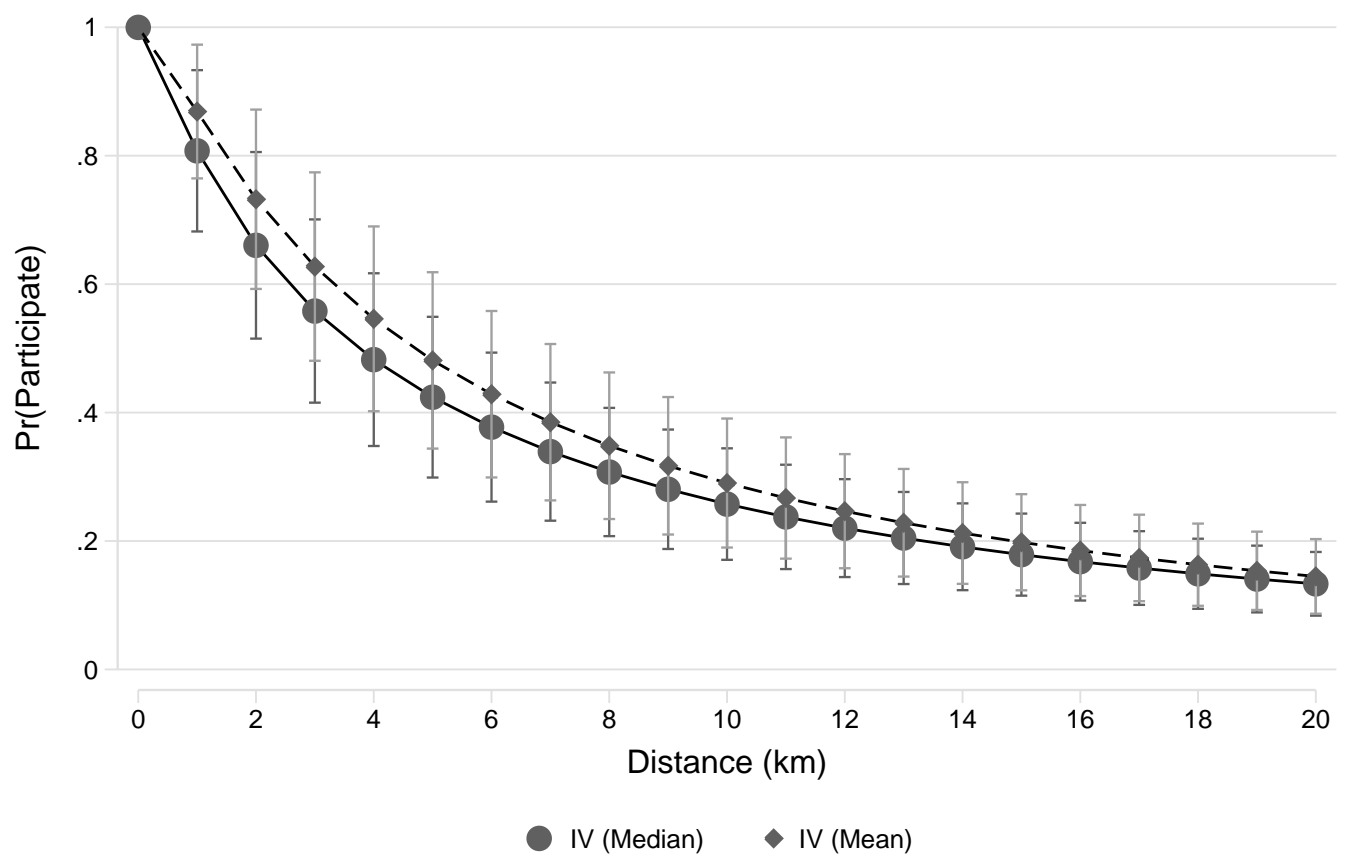

Figure 6: Average probability of participating using median or mean distance measures. 
However, the overall result does not change; that distance has a substantial impact on the participation decision. Even in the $25 \mathrm{~km}$ case, the probability of entering a tender decreases from close to unity for very short distances to around 35 percent for a distance of $20 \mathrm{~km}$. When consulting the results for the rival's distance coefficients, the same pattern as in Figure 4 appears, and the inferences remain the same.

In a second sensitivity analysis, the average distance from the contract was used instead of the median. The results are shown in Figure 6 and indicate that using the average distance shifts the curve up by a couple of percentage points. The difference is, however, not statistically significant and does not change the results or inferences.

\section{Results discussion}

It has been shown in the previous section that the operator's distance to tendered contracts affects their probability to participate in tenders. The overall result is that the operator's probability of participating is close to unity for a distance close to zero, but this probability decreases rapidly as the distance is increases and is only some 30 percent already at 10 kilometers. The rapid decrease implies that dead running is an important factor for operators, and thus for their likelihood to bid on a tender. Therefore, contract areas need to be designed in such a way that multiple operators are close by, especially small and mid-sized operators. Of course, this is not always possible. However, the PTA should not necessarily stick with the old contract area designs in new tenders, which is often the case today. This is especially important because operators are often unevenly distributed over the area, as opposed to the situation in the London study by Iossa and Waterson (2017).

The results from the participation model show that large operators are less sensitive to distance than are co-ops and other operators. This supports the argument that large operators have greater knowledge and skills in bidding on tenders and more experience in establishing new services in new areas. This argument can also be strengthened if viewed from the smaller operators' perspective. Arguably, the smallest operators only care about one, or possibly a few, contracts in their local municipal area, perhaps run by the same company for decades. In accordance with the results, such operators have a relatively low maximum distance threshold for deciding to bid on a tender. These thresholds probably increase with company size, but in many cases the county border is likely to be the frontier of most companies. The same argument could be made for co-ops because they are made up by smaller operators. With its members spread out over the county, they can utilize their common resources to minimize dead running, but they might still have a relatively low distance threshold for participating.

Another aspect where large operators differ is when the PTA includes a depot in the contract. While large operators are more inclined to participate in such contracts, co-ops and other operators are not influenced by such an offer. The former result is expected because depots are a fundamental resource for transport 
provision and offering one for use might serve to lower entry barriers. For co-ops and other operators, a likely explanation is that these already have depots in place in the contract area and that the additional depot would potentially only incur more costs and thus they participate anyways.

To attract more large operators to their tenders, a straightforward policy suggestion for the PTAs would be to offer more depots. However, the situation is likely to be more complex. First, 65 percent of the contracts already see at least one large operator participating, and 40 percent see two participating. Further, even if the PTA manages to attract more bidders, the results of Tukiainen (2008) suggesting a common cost environment in bus contracts imply that participants might not lower their bids despite increased competition. Cantillon and Pesendorfer (2006) however, argue for a private cost environment. Second, establishing a new depot is likely to be costly in monetary terms, but also in the work effort needed by the PTA in choosing where to put it. Depots need a washing facility, garage, and possibly maintenance space, all of which are costly to acquire, build, and maintain. Therefore, a relatively high bid reduction is needed for the investment to break even. Rather, the PTAs' strategy should be to keep depots they already own. If, however, depots were to be established, they might be more important in more urban areas (most notably the cities of Stockholm, Gothenburg, and Malmö) where depot capacity is likely to be extremely hard to find without the help of the PTA. This indeed seems to be the strategy of the Stockholm PTA.

Finally, some more attention is given to co-ops, which have an advantage in that their individual members have depots spread across a given area. This increases the scope for minimizing the costs of dead running through cooperation. The cooperation is justified on the basis that the small members alone could not compete for some bigger contracts, which they can as members of the co-op by enjoying economies of scale. This way the operators also enhance the competitive environment within the county as well as nationwide and avoid a potential oligopoly situation among the largest operators. However, the cooperation of the co-op operators' members limits the scope for other operators to enter the market because potential partners (the local operators) are already reserved for the co-op. That is, outside operators cannot work together with existing operators to complement their new network of depots. Cooperation of this sort is not unusual in the tendering market, but such long-lasting partnerships, not seldom since the 1980s, are probably not and should raise concerns. Because the size of the co-op members varies greatly ${ }^{10}$, the economies of scale argument is likely not to hold entirely, and the dominance of co-ops mostly in the northernmost counties should raise concerns. The recent tendering in Västernorrland in 2013 could serve as an example, where a co-op was the only bidder for 7 of 15 contracts, mostly run in rural areas. In short, co-ops can well enhance competition, but they can also substantially limit it. Especially in the long-run.

\footnotetext{
${ }^{10}$ Buss i Väst, Mittbuss, and Sambus, the largest operators in each co-op, each own 140-200 buses, while the smaller are in the range of 1-5 buses. Source: Swedish Bus and Coach Federation (2017) and own research.
} 


\section{Conclusions}

This paper is concerned with operators' distance to tendered bus contracts and what effect this has on their probability to participate in tenders. Distance translates to dead running kilometers in traffic provision, which in turn leads to higher costs for the operators, and potentially even for the PTAs, which in turn could reduce participation in tenders. Using contract data on bus tenders along with operator workplace data, probit regressions were carried out to determine the impact of distance from workplaces to contracts, as well as to investigate the impact of heterogeneous operators and the inclusion of depots in the tender.

The most important result was that distance matters for the operators' probability to participate in a tender, and that this probability decreases rapidly with increasing distance. While operators close to the contracts (0-1 kilometers) were almost certain to participate, this probability decreased rapidly and was only 30 percent at 10 kilometers away. This probability however, varied depending on how the estimation sample was used. This is evidence that the local competitive environment is important when designing bus contracts. In addition, the rival's distance to the contract had a small but statistically significant impact on an operator's participation decision. However, the operator's own distance is still the most important factor. Also, this paper found that large operators seem to be less sensitive to the distance of the contract and that they are more likely to enter a bid if the PTA offers a depot as part of the tender. The same did not hold for co-ops or other operators. 


\section{References}

Bajari, P. and Ye, L. (2003). Deciding between competition and collusion. Review of Economics and statistics, 85(4):971-989. Cantillon, E. and Pesendorfer, M. (2006). Auctioning bus routes: the London experience. In Cramton, P. C., Shoham, Y., and Steinberg, R., editors, Combinatorial Auctions, chapter 22. MIT Press, Cambridge.

Cantillon, E. and Pesendorfer, M. (2007). Combination bidding in multi-unit auctions. CEPR discussion paper 6083.

Chamberlain, G. (1980). Analysis of covariance with qualitative data. The Review of Economic Studies, 47(1):225-238.

Chamberlain, G. (1982). Multivariate regression models for panel data. Journal of Econometrics, 18(1):5-46.

Flambard, V. and Perrigne, I. (2006). Asymmetry in procurement auctions: Evidence from snow removal contracts. The Economic Journal, 116(514):1014-1036.

Greene, W. H. (2003). Econometric analysis. Pearson Education.

Hensher, D. A. (2015). Using contracted assets to undertake non-contracted services as a way to improve cost efficiency under negotiated or tendered bus contracts. Journal of Strategic Contracting and Negotiation, 1(2):111-128.

Hensher, D. A., Mulley, C., and Smith, N. (2013). Towards a simplified performance-linked value for money model as a reference point for bus contract payments. Research in Transportation Economics, 39(1):232-238.

Hensher, D. A. and Wallis, I. P. (2005). Competitive tendering as a contracting mechanism for subsidising transport: The bus experience. Journal of Transport Economics and Policy, 39(3):295-322.

Iossa, E. and Waterson, M. (In Press, 2017). Maintaining competition in recurrent procurement contracts: A case study on the London bus market. Transport Policy.

Jofre-Bonet, M. and Pesendorfer, M. (2003). Estimation of a dynamic auction game. Econometrica, 71(5):1443-1489.

Kennedy, D. (1996). The economics of London bus tendering. PhD thesis, London School of Economics and Political Science.

Kepaptsoglou, K., Karlaftis, M. G., and Bitsikas, T. (2009). Bus-to-depot allocation: models and decision support system. Journal of Transportation Engineering, 136(7):600-605.

Lancaster, T. (2000). The incidental parameter problem since 1948. Journal of Econometrics, 95(2):391-413.

Lewis, G., Bajari, P., et al. (2011). Procurement contracting with time incentives: Theory and evidence. The Quarterly Journal of Economics, 126(3):1173-1211.

Lundberg, S., Marklund, P.-O., Strömbäck, E., and Sundström, D. (2015). Using public procurement to implement environmental policy: an empirical analysis. Environmental Economics and Policy Studies, 17(4):487-520.

Mahadikar, J., Mulangi, R. H., and Sitharam, T. G. (2015). Optimization of bus allocation to depots by minimizing dead kilometers. Journal of Advanced Transportation, 49(8):901-912.

Mathisen, T. A. and Solvoll, G. (2008). Competitive tendering and structural changes: An example from the bus industry. Transport Policy, 15(1):1-11.

McFadden, D. (1974). Conditional logit analysis of qualitative choice behavior. In Zarembka, P., editor, Frontiers in econometrics, pages 105-142. Academic Press, New York.

Mundlak, Y. (1978). On the pooling of time series and cross section data. Econometrica, pages 69-85.

Neyman, J. and Scott, E. L. (1948). Consistent estimates based on partially consistent observations. Econometrica, 16(1):1-32.

Nilsson, J.-E. (2011). Kollektivtrafik utan styrning. ESO report 2011:6.

Prakash, S., Balaji, B., and Tuteja, D. (1999). Optimizing dead mileage in urban bus routes through a nondominated solution approach. European Journal of Operational Research, 114(3):465-473.

Preston, J. (1992). Competition policy and the british bus industry: The case of mergers. In Proc. 2nd International Conference on Competition and Ownership in Land Passenger Transport (Thredbo 2), Tampere, Finland.

Schunck, R. (2013). Within and between estimates in random-effects models: Advantages and drawbacks of correlated random effects and hybrid models. Stata Journal, 13(1):65-76. 
Somaini, P. (2011). Competition and interdependent costs in highway procurement. Unpublished manuscript. http: //economics.yale.edu/sites/default/files/somaini-120906.pdf.

Swedish Bus and Coach Federation (2017). Statistik om bussbranchen, Mars 2017 (Statistics on the bus industry, March 2017). Report (in Swedish).

Transport Analysis (2017). Local and regional public transport 2016. Retrieved from tables at http://www.trafa.se/ kollektivtrafik/kollektivtrafik/.

Tukiainen, J. (2008). Testing for common costs in the city of Helsinki bus transit auctions. International Journal of Industrial Organization, 26(6):1308-1322.

Vigren, A. (2017). How many want to drive the bus? Analyzing the number of bids for public transport bus contracts. Unpublished manuscript. Available upon request from andreas.vigren@vti.se.

Wallis, I. and Bray, D. (2001). Competitive tendering for bus services: The improved Adelaide model. In Proc. 7th International Conference on Competition and Ownership in Land Passenger Transport (Thredbo 7), Molde, Norway.

Wooldridge, J. M. (2010). Econometric analysis of cross section and panel data. MIT press. 


\section{Appendix A. Full results table}

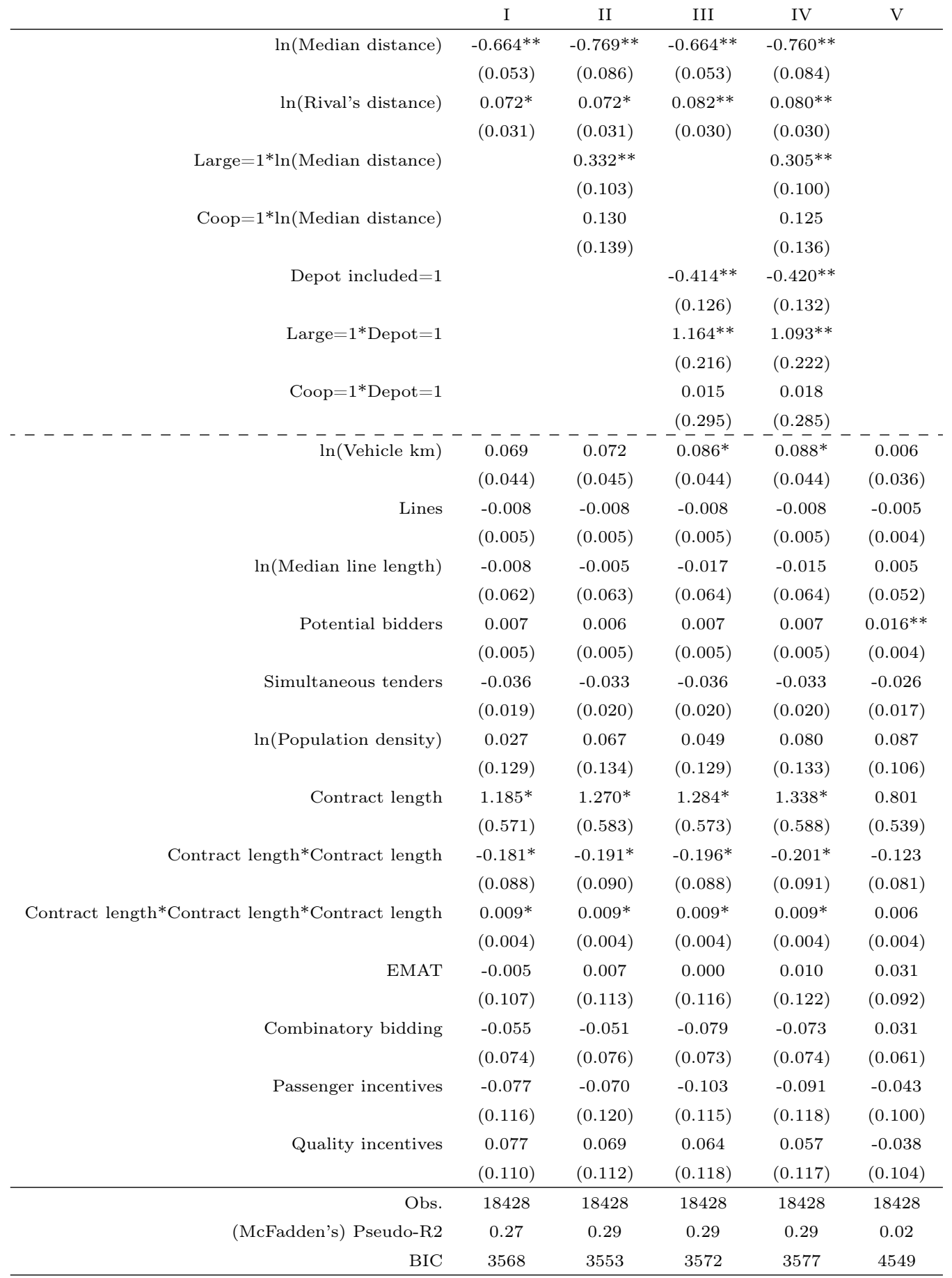

Table continues on next page...

Table A.5: Full results table (part 1) 


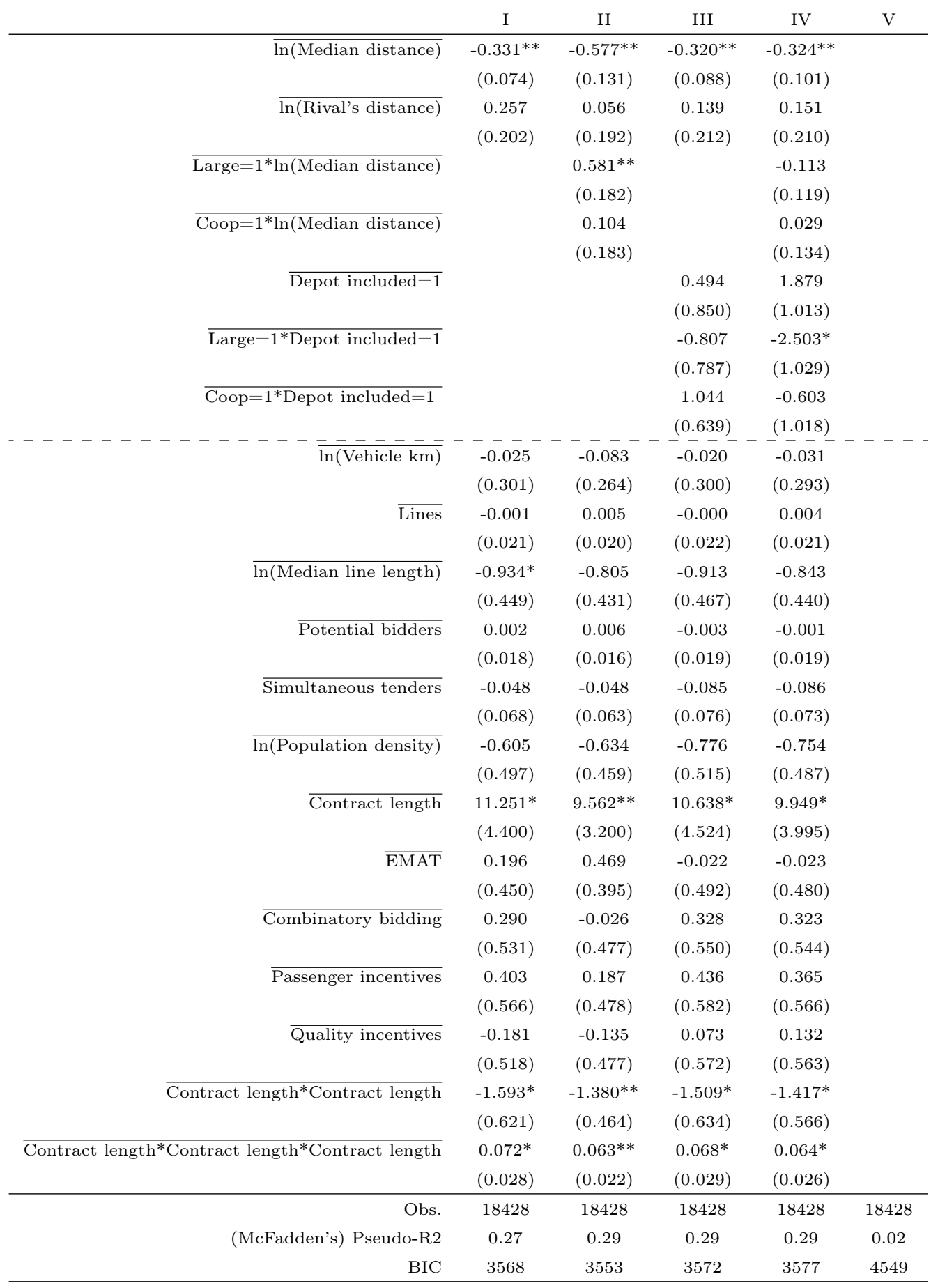

** $p<0.01,{ }^{*} p<0.05$. Cluster robust standard errors at operator-workplace level in parenthesis

Table A.6: Full results table (part 2) 


\section{Appendix B. Sensitivity test}

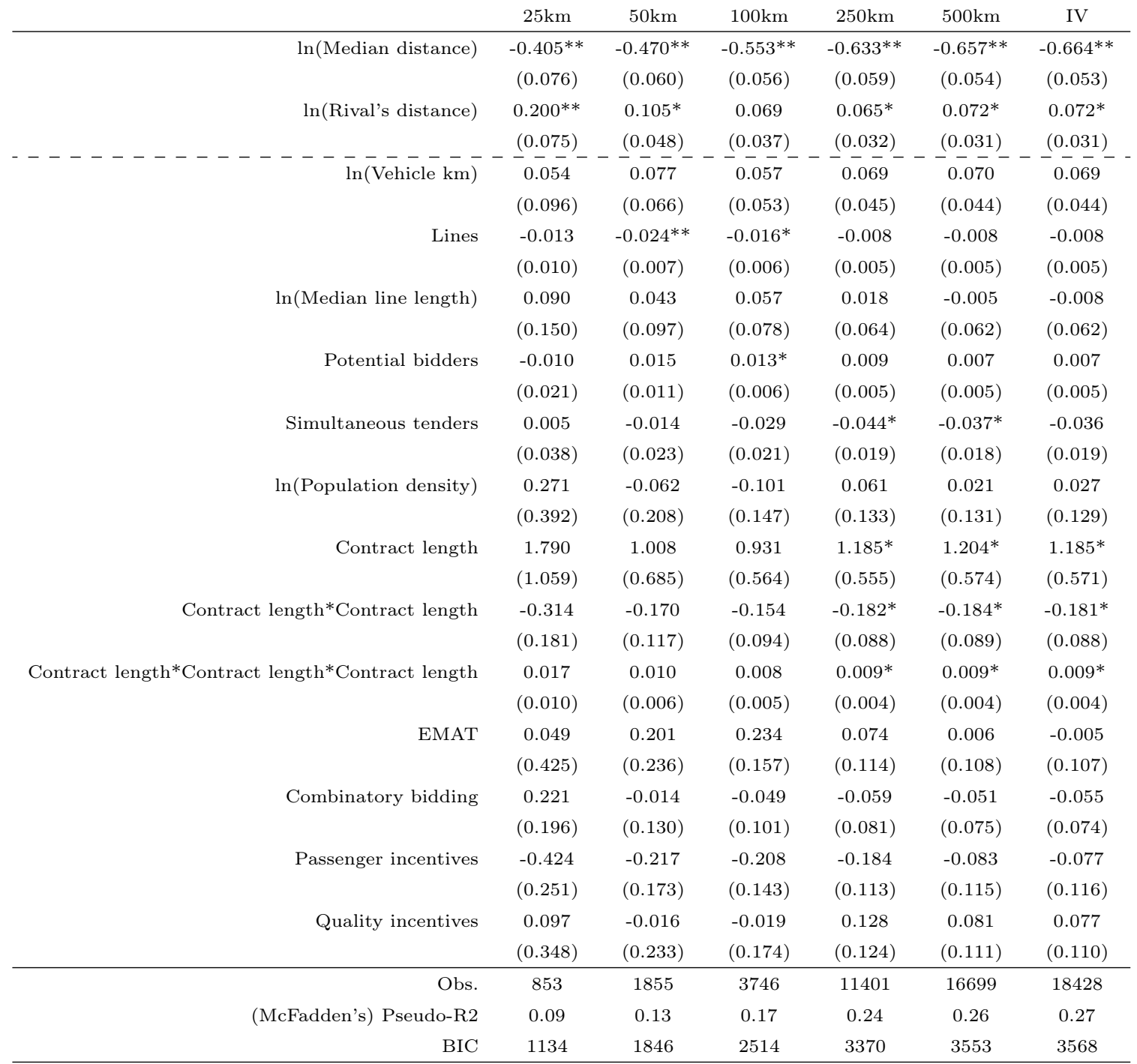

** $p<0.01, * p<0.05$. Cluster robust standard errors at operator-workplace level in parenthesis

Table B.7: Full result table, sensitivity tests 